\title{
Challenges of preserving modernist concrete
}

\author{
Ann Harrer ${ }^{* 1}$ and Paul Gaudette ${ }^{2}$ \\ ${ }^{1}$ Associate Principal, Wiss, Janney, Elstner Associates, Los Angeles, California, United States \\ ${ }^{2}$ Principal, Wiss, Janney, Elstner Associates, Chicago, Illinois, United States
}

\begin{abstract}
Exposed architectural concrete is often a defining characteristic of modernist structures. Concrete, like other construction materials, eventually deteriorates over time and with exposure to environmental factors. With any historic structure, challenges exist in the development of an appropriately sensitive rehabilitation strategy to address existing distress, including structural repairs, use of compatible materials, development of repair procedures without unnecessary removal of historic material, and sustainable practices, as well as to meet the requirements of governing standards or jurisdictions. It is important to understand the structure's construction, including material constituents of the concrete, unique characteristics, and extent and causes of deterioration, as well as project requirements and goals. Following a condition assessment, the rehabilitation strategy can be developed, taking into account the sensitive nature of the structure. Appropriateness and compatibility of repairs, together with technical soundness, are key to the success of the repair design. In addition, poor or incomplete repairs will have a minimal service life and can result in additional distress or other problems with the structure. This paper will describe challenges encountered in the preservation of modern concrete structures, focusing on architectural concrete. Case studies of several iconic modernist concrete structures, including the Salk Institute for Biological Studies in La Jolla, California, for which the authors have developed that highlight approaches to address these challenges.
\end{abstract}

\section{Introduction}

Concrete has been a popular construction material since antiquity and has been utilized by the modern construction industry for well over a century. Concrete gained acceptance in modern construction because it offered the advantages of conforming to virtually any shape and was readily adaptable to various architectural finishes. As development of new admixtures and additives continues, the possibilities of concrete construction appear limited only by the creativity of the designer.

As a fireproof material, concrete's popularity increased as cities rapidly expanded in the early twentieth century. Later, as understanding of concrete's advantages and potential grew, it became extensively employed not only for the structural elements but also for exposed architectural surfaces at both the exterior and interior of buildings.

Concrete, like other construction materials, eventually deteriorates over time and with exposure to environmental factors. Primary causes of concrete deterioration are usually related to freezing and thawing of critically saturated concrete, corrosion of embedded metal, materials problems, or issues during original construction, such as insufficient concrete cover for reinforcement. The nature and severity of each type of deterioration depend upon the climate and other conditions of environmental exposure (such as pollutants and/or chlorides) [1]. Deterioration and distress can also be related to structural issues such as overloading, or natural disasters such as earthquakes.

While similar processes and procedures are utilized for the assessment and repair of any concrete structure, additional investigation may be necessary for historic structures.

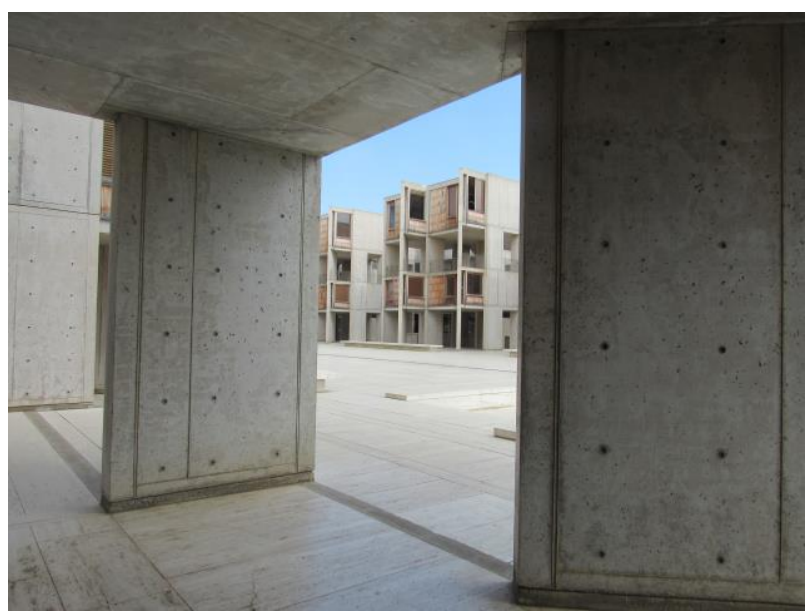

Fig. 1. Exposed concrete finish at the Salk Institute for Biological Studies, designed by Louis Kahn. Photo by the authors.

\footnotetext{
* Corresponding author: aharrer@wje.com
} 
In addition, the development of repairs may be complicated due to the original construction methods, exposed finish, conservation of historic fabric, or other factors. Additional challenges are presented by modernist concrete structures. Consideration of the significance of the concrete structure, preservation goals, and limitations on repairs and modifications need to be addressed as part of the repair design and should be reviewed with the owner of an architecturally significant and historic property during the initial stages of the project.

\section{Modernist concrete characteristics}

Widely used in Modernist architecture, concrete essentially defined the Brutalist architecture movement, named after the French term béton brut, meaning raw concrete. Architects such as Le Corbusier, Erno Goldfinger, Marcel Breuer, and others pioneered the Brutalist movement. Other modern architects such as Louis Kahn, Tadao Ando, Minoru Yamasaki, and Welton Becket continued the use of concrete as architectural elements in their designs.

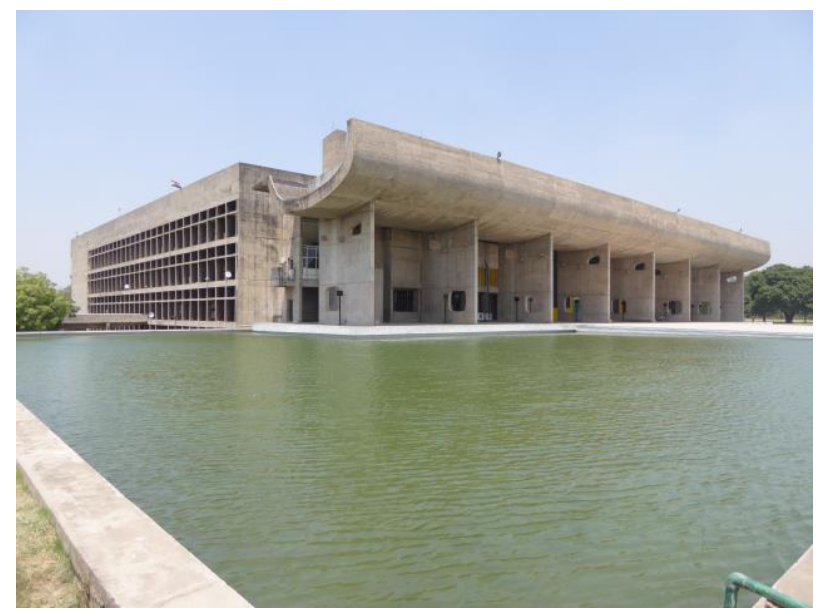

Fig. 2. Exposed concrete finish at the Legislative Assembly in Chandigrah, India, designed by Le Corbusier. Photo by the authors, 2016

One defining characteristic of modernist concrete structures is that the finish of the exterior of the building often is exposed concrete. The exterior is detailed and defined by the concrete material, placement method, and finishing procedures. Figures 1 through 3 are examples of exposed concrete finishes of modernist concrete structures.

In the design of concrete as a modernist architectural material, care and attention was paid to the material constituents utilized as well as to construction methods, as these factors would directly impact the overall aesthetic. By varying the amount and type of material constituents, including the aggregates and cements, the material properties and color of the concrete can be adjusted.

Construction methods and finishing techniques directly affect the final surface appearance and texture.

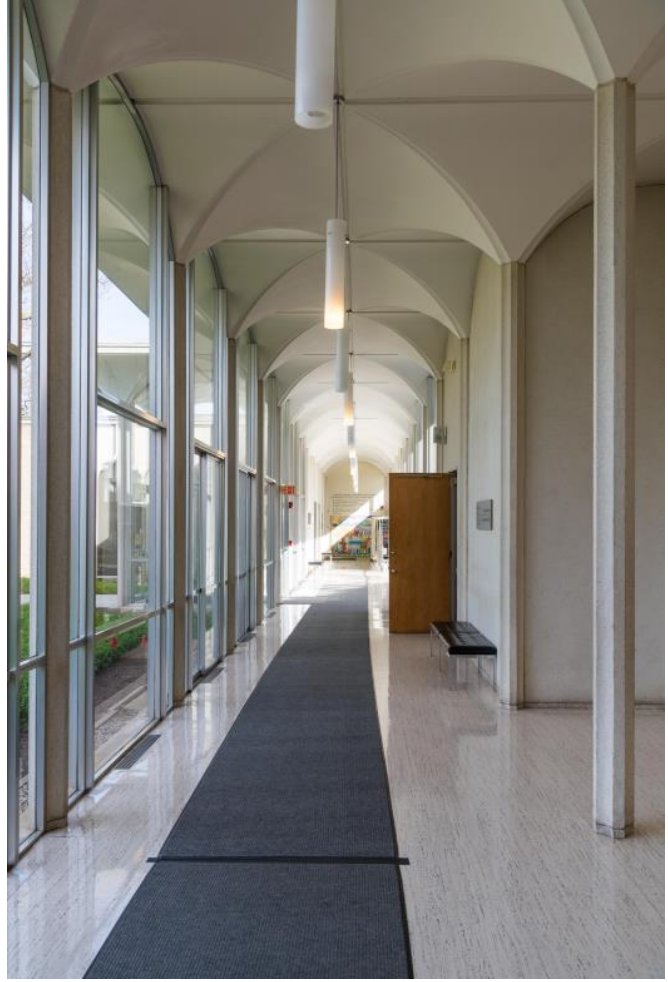

Fig. 3. Exposed interior concrete architectural elements at North Shore Congregation Israel in Glencoe, Illinois, designed by Minoru Yamasaki. Photo by the authors.

Some of the various finishing techniques used historically as well as today included exposing the aggregates, retaining the texture from the formwork for a rougher finish (board form), and rubbing to create a smooth finish (Figure 4).

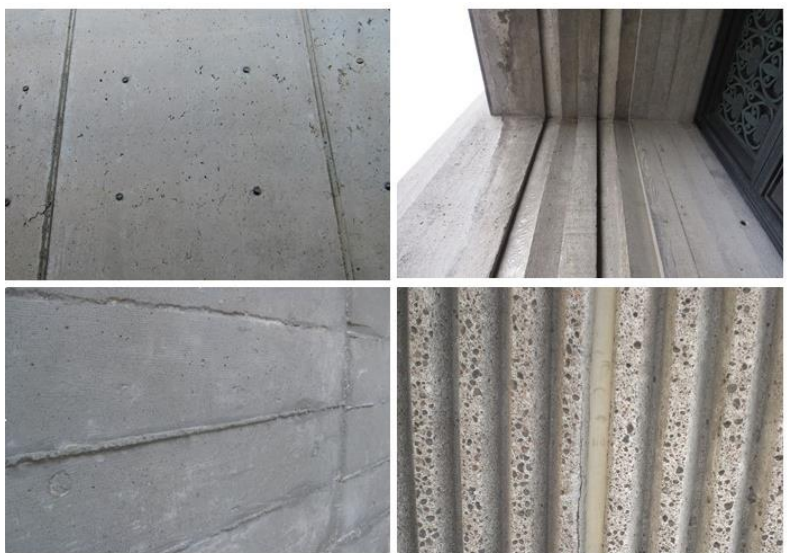

Fig. 4. Examples of variations in the exposed concrete finish in modernist concrete structures. Photos by the authors.

\section{Assessment}

As an initial step in the development of a rehabilitation strategy for a modernist concrete structure, an assessment of the concrete structure should be performed to evaluate existing conditions and determine causes of distress and deterioration. The findings of the assessment provide the basis for development of a rehabilitation strategy that typically includes a repair and maintenance program. The assessment should also include 
identification and documentation of historically or architecturally significant components. An understanding of the original construction as well as of deterioration mechanisms provides information to support development of the repair and maintenance program.

The condition assessment should include, at a minimum, the following:

1. Significance - The significance of the concrete and defining features of the structure should be determined.

2. Research - Prior to the field investigation, information relevant to the original construction, techniques, materials, use, maintenance, and modification of the structure should be gathered and reviewed.

3. Field Investigation - The field investigation should include the observation and documentation of the structure, including verification of as-built construction and identification of architecturally or historically signifiant elements, and documentation of deterioration and distress (Figure 5).

4. Field and Laboratory Testing - Visual observations should be supplemented with nondestructive evaluation methods, exploratory openings, and laboratory analysis to determine deterioration mechanisms, material constituents, and as-built conditions.

5. Evaluation of Findings - Findings from the research, field investigation, and testing are compiled and analyzed to inform the appropriate scope of rehabilitation or repair.

The first step is to research the history and significance of the building, the concrete, and its character-defining features. For example, is the finish board-formed, exposed aggregate, or covered with an architectural coating? If exposed, what is the color and texture of the concrete surface? Research should include collecting and reviewing as much information as possible regarding the original construction, use, repair, previous assessments, and maintenance of the concrete.

The next step is to perform an on-site field investigation, and field and laboratory testing $[2,3]$. The resulting data informs a report that serves as a summary of findings and, taking into consideration the owner's project requirements and significance of the concrete structure, provides the basis for the development of a conservation approach.

\section{Conservation Approach Development}

The conservation and repair approach for a modernist concrete structure is developed following the completion of a condition assessment. The findings from the condition assessment are studied to determine the underlying causes of observed deterioration and distress.

In some cases, structural assessment and analysis may be necessary, for example if as-built conditions are found to be different than anticipated (e.g., less reinforcement in the structure than shown in construction documents).

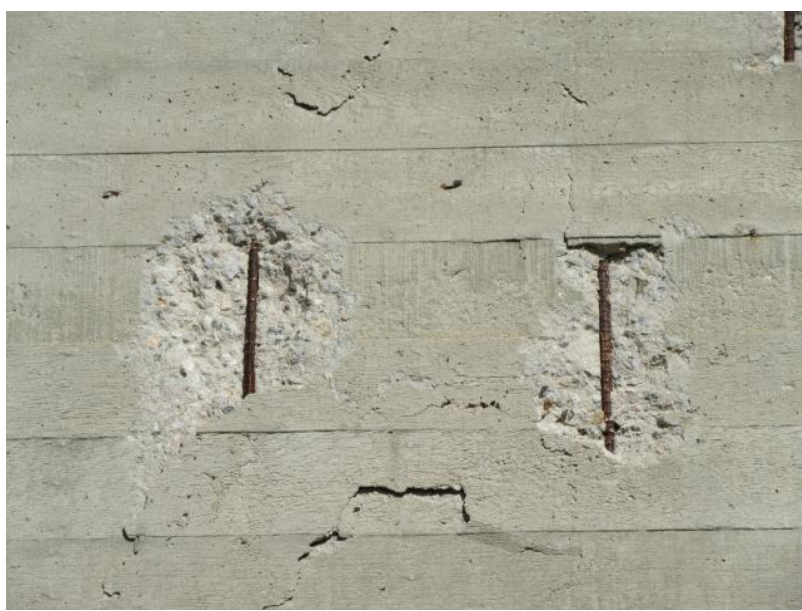

Fig. 5. Delamination and spalling at exposed concrete are examples of distress and deterioration that should be documented as part of a visual condition survey. Photo by the authors.

The causes of observed deterioration and distress should be understood in order to develop an appropriate scope and define the extent of repairs. The owner's intended use and maintenance of the structure as well as the significance and value of the structure should also be understood and considered. Through evaluation of the assessment findings, taking into consideration the owner's project goals, a conservation approach can be developed to address concerns while being sensitive to the preservation of the historic fabric.

The rehabilitation approach needs to consider technical concerns, such as deterioration mechanisms and durability, characteristics of the original concrete as well as the aesthetic considerations of matching the original concrete elements [4]. Most importantly, the rehabilitation approach should address the underlying causes of the distress or deterioration of the concrete to minimize continued deterioration or premature failure of the repairs. This may require removal of historic fabric, such as in cases where removal of concrete to access all sides of a corroded bar is necessary to mitigate the ongoing corrosion (Figure 6). Removal behind existing reinforcement bar also allows for repair material to be mechanically anchored.

Repairs to the concrete structure should be durable and extend the service life of the concrete structure. It is therefore important that the repair approach includes surface preparation of the substrate to achieve bond of the repair material to the original concrete substrate. The characteristics of the original concrete should be considered in the characteristics of the repair material and design of the repair itself [5]. For example, the compressive strength and modulus of elasticity of the repair material need to be compatible with the original or substrate concrete. In addition, the depth and shape of the repair should be selected to provide durable service life to both the repair and the substrate concrete.

As previously noted, in modernist concrete structures the exterior finish is often exposed concrete.

Therefore, the conservation approach should take into account matching of the existing overall aesthetic of the concrete including the color, texture, and finish, 
while maintaining the durability of the structure and addressing the underlying cause of distress.

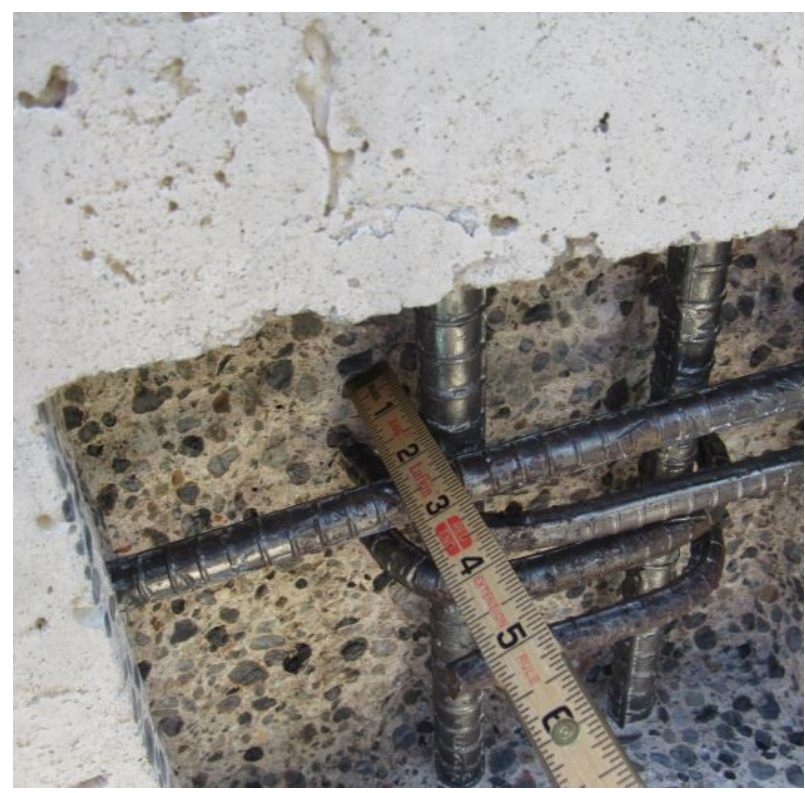

Fig. 6. Removal of concrete beyond the corroding reinforcement bar to allow removal of corrosion product and to address underlying distress mechanism. Photo by the authors.

Research and consideration of available cements, aggregates, and potentially admixtures to develop a compatible mix that is a color match to the original is necessary. Locally available materials may have been sourced during original construction that are available, however, it should be noted that material removed from the same quarry but from a different depth or location may not be similar to the original constituents. Available mineral pigments and admixtures should be considered to achieve a color match, however, the durability and color steadfastness of the materials needs to be understood. Matching the existing geometry and finish may affect the constructability of the repair, a factor that needs to be considered.

\section{Repair Implementation}

The results of architectural concrete repair work are dependent to a great extent on the experience of the concrete repair contractor and the level of craftsmanship of the person performing the work. Prior to the start of an architectural concrete repair project, it is important that a mock-up and trial repair program be performed. As the level of craftsmanship of anyone implementing the repairs is critical to the overall technical performance as well as the final aesthetic, it is imperative to establish the desired level of craftsmanship prior to the start of work. Mock-ups and trial repairs are necessary to confirm the developed rehabilitation approach (Figure 7).

The design of the concrete repair mix design needs to be developed to achieve technical specifications outlined in the rehabilitation approach as well as to match the adjacent original concrete. The mix development, review and approval process can require quite a bit of time and should be included in the construction schedule. It is also important that the concrete mix be designed for constructability to allow for placement. Typically formed concrete repairs are preferable over trowelapplied mortars for several reasons. For example, concrete repair materials will have more characteristics similar to the substrate concrete. The mix design developed for the repairs should be compatible with the characteristics of the original concrete. Prior to the start of work, off-building samples and mock-ups should be prepared to demonstrate constructability, performance, and aesthetic characteristics of the repair material.

The design of formwork and finishing procedures of the concrete need to be developed to match the existing concrete. In order to achieve compatible, durable, and aesthetically matching repairs, the creation of formwork, placement procedures, and finishing procedures need to be practiced and finalized through a series of offbuilding samples and mock-ups [6]. Only during the offbuilding samples and mock-ups can mixes, placement, and finishing procedures be fine-tuned and modified without resulting in unacceptable repairs on the building that will require removal.

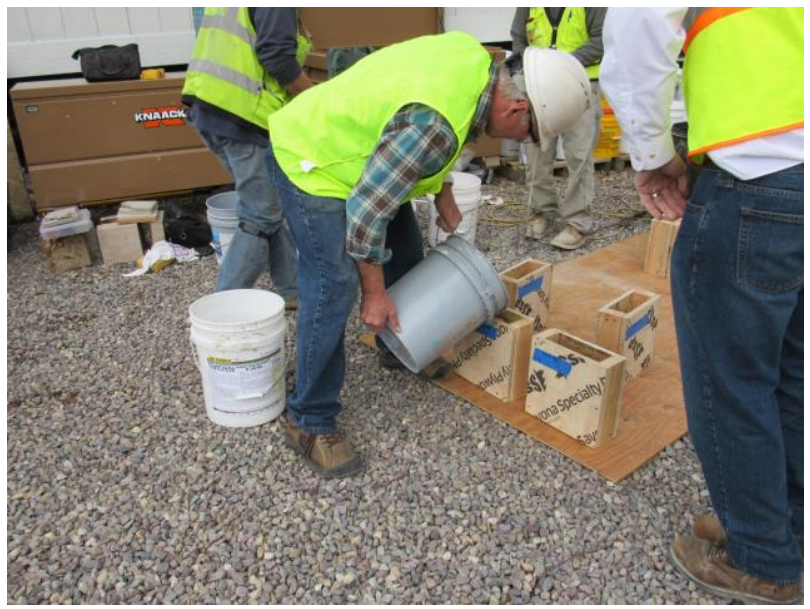

Fig. 7. Completion of off-building trial samples and mock-ups prior to the start of repairs to confirm appropriate performance of the concrete mix design, placement procedures, and finishing techniques. Photo by the authors.

The successful completion of samples, mock-ups, and trial repairs will demonstrate the level of craftsmanship, the ability to achieve the necessary technical characteristics, and the match to the aesthetic details of the existing structure. Production repair work can then begin. Trial concrete repair work at the building should be completed to achieve the desired craftsmanship level established during the samples and mock-ups. During the implementation of the concrete repairs, craftsmanship needs to be maintained at a high level to achieve a final result that is acceptable and matches the existing concrete in color, finish, and texture. During the repair work quality control measures, including sampling and testing of plastic and hardened concrete is recommended. Field testing should include monitoring the batching and mixing of the concrete repair materials with slump, air content, unit weight, and other typical quality control testing. Cylinders should be cast and compressive strength testing conducted regularly. In addition, testing of the repairs, once adequately cured, to confirm 
adequate bond to the substrate should be completed. This testing should consist of hammer sounding to detect any areas of unsound or unbonded repair materials. Additional quality control testing, including tensile bond testing can also be performed. If any repairs deviate from the approved mock-ups, are unsound, or do not match the adjacent concrete, these can be removed and replaced.

\section{Summary}

The use of concrete as both an architectural and structural material has created challenges, particularly in modernist structures where the concrete is a defining feature of the building. Understanding the significance of a modernist structure and conserving the concrete defining features are vital to the preservation of these modernist structures. Concrete is susceptible to deterioration as a result of various distress mechanisms, from environmental exposure to problematic original design and construction. The first step in the preservation of a modernist concrete structure is the condition assessment to identify architecturally or historically significant characteristics, to understand asbuilt construction, and to determine the extent and cause of distress and deterioration. The preservation approach needs to address the underlying deterioration or distress mechanisms while matching the existing original color, finish, and texture of the concrete structure. The repair implementation requires a high level of contractor experience and craftsmanship to retain the overall design aesthetic of the structure. The completion of mock-ups and trial repairs is essential to establish standards for the overall repairs.

\section{References}

1. Gaudette, Paul, and Deborah Slaton. Preservation Brief 15: Preservation of Historic Concrete. Washington D.C.: National Park Service, Heritage Preservation Services, 2007.

2. American Concrete Institute. Guide to Evaluation of Concrete Structures before Rehabilitation. ACI Committee 364, ACI 364.1R-19.

3. Gaudette, Paul, and Ann Harrer, "Assessment of Historic Concrete Structures," Practice Points Number 16, APT Bulletin: The Journal for Preservation Technology 48, no. 4, 2017.

4. American Concrete Institute. Guide to Concrete Repair. ACI Committee 546, ACI 546R-14.

5. Gaudette, Paul, Deborah Slaton, and David Patterson, "Morse and Ezra Stiles Colleges, Yale University, New Haven, Connecticut USA 19581963," Concrete: Case Studies in Conservation Practice, Conserving Modern Heritage. Los Angeles: Getty Conservation Institute, December 2018.

6. Caldwell, Jeffrey and Ann Harrer, "Repairs to Concrete at the Pilgrimage Theatre in Los Angeles, California," APT Bulletin: The Journal for Preservation Technology 48, no 1, 2017

\section{Acknowledgements}

Deborah Slaton, FAPT, a principal with Wiss, Janney, Elstner Associates, Inc., is gratefully acknowledged for her constructive and detailed reviews. 